\title{
PSEUDO JAHN-TELLER ORIGIN OF THE PROTON TUNNELING IN ZUNDEL CATION CONTAINING WATER CLUSTERS ${ }^{1}$
}

\author{
ION GERU, NATALYA GORINCHOY, IOLANTA BALAN
}

PACS 03.65.Xp, 71.70.Ej (C) 2012
Institute of Chemistry, Academy of Sciences of Moldova

(3, Academiei Str., Kishinev MD-2028, Republic of Moldova; e-mail: iongeru@ yahoo. com)
The pseudo Jahn-Teller (PJT) origin of the proton transfer barrier in the Zundel cation at different $\mathrm{O}-\mathrm{O}$ distances and in an $\mathrm{H}_{5} \mathrm{O}_{2}^{+}\left(\mathrm{H}_{2} \mathrm{O}\right)_{4}$ cluster is revealed by means of $a b$ initio calculations of their electronic structures and the adiabatic potential energy curves. The vibronic constants in this approach were estimated by fitting the $a b$ initio calculated adiabatic potential to its analytical expression. It is shown also that the high-symmetry nuclear configurations of proton-centered water clusters of the type $\mathrm{H}^{+}\left(\mathrm{H}_{2} \mathrm{O}\right)_{n}(n=6,4,3)$ are unstable with respect to the lowsymmetry nuclear distortions leading to forming the dihydronium cation $\mathrm{H}_{5} \mathrm{O}_{2}^{+}$and the appropriate number of water molecules: $\mathrm{H}_{2 n+1} \mathrm{O}_{n}^{+} \rightarrow(n-2) \mathrm{H}_{2} \mathrm{O}+\mathrm{H}_{5} \mathrm{O}_{2}^{+}$. The reason for this instability and the subsequent decay is the PJT coupling between the ground and excited electronic states.

\section{Introduction}

Protonated water clusters of different dimensions $\mathrm{H}^{+}\left(\mathrm{H}_{2} \mathrm{O}\right)_{n}$ are taken as a convenient microscopic model in studying the proton transfer in liquid water. They are the subject of numerous experimental and theoretical investigations (see, for example, [1-5] and references therein). Quantum chemical calculations of such clusters available from the literature are devoted manly to the determination of the equilibrium geometrical parameters of their lowest-energy isomers. The other goal of such calculations is the elaboration of pre-parametrized analytic potential models that could be used to simulate the proton transfer reaction.

\footnotetext{
1 This work was presented at the 5th International Conference "Physics of Liquid Matter: Modern Problems" (Kyiv, Ukraine, 2010)
}

In the present work, the pseudo Jahn-Teller effect (PJTE) is employed to rationalize the results of $a b i n i-$ tio calculations of adiabatic potential energy surfaces (APES) for a series of protonated proton-centered water clusters and to demonstrate its efficiency in considering the systems with hydrogen bonds. Many works on molecular and solid-state systems [6-9] show that the analysis of the excited states coupled to the ground state via appropriate vibrational modes provides valuable knowledge on the causes giving rise to asymmetric (off-center) atomic displacements. In systems with hydrogen bonds, a quantitative PJT analysis was first used in [10] to study the origin of the hydrogen bond (HB) in the proton-bound ammonia dimer cation $\mathrm{N}_{2} \mathrm{H}_{7}^{+}$. It was shown there that this approach reveals many details that will prove useful for understanding the HB molecules.

In this work, we first analyzed the possibility of the formation and the existence of proton-centered water clusters of the type $\mathrm{H}^{+}\left(\mathrm{H}_{2} \mathrm{O}\right)_{n}(n=6,4,3)$. For this purpose, the electronic structure of $\mathrm{H}^{+}\left(\mathrm{H}_{2} \mathrm{O}\right)_{n}$ clusters is calculated, and their instability with respect to the decay $\mathrm{H}_{2 n+1} \mathrm{O}_{n}^{+} \rightarrow(n-2) \mathrm{H}_{2} \mathrm{O}+\mathrm{H}_{5} \mathrm{O}_{2}^{+}$is studied. Particular attention was paid to the analysis of the instability of high-symmetry $D_{2 d}$ nuclear configurations of the dihydronium cation $\mathrm{H}_{5} \mathrm{O}_{2}^{+}$(Zundel cation) and the $\mathrm{H}_{5} \mathrm{O}_{2}^{+}\left(\mathrm{H}_{2} \mathrm{O}\right)_{4}$ cluster that includes the first solvation shell of $\mathrm{H}_{5} \mathrm{O}_{2}^{+}$with respect to the proton transfer from one water molecule to another one. In all the cases, we started our investigation from the most possible highsymmetry configuration of the systems under consideration, analyzed their distortions, and demonstrated that a distortion of the whole cluster accompanied by a lowering of the symmetry of its nuclear configuration is due to the pseudo Jahn-Teller effect. 


\section{Methods}

\subsection{Computational details}

All calculations were performed, by using the PC GAMESS version [11] of the GAMESS (US) QC package [12]. A rather flexible basis set of the triple-zeta quality (TZV) [13] augmented with polarization functions was used throughout the calculations. At the first step, the geometry of all considered proton-centered water clusters in their highest possible symmetry was optimized in the frame of the RHF SCF method. Then, the electronic correlation was taken into account via the configuration interaction (CI) with single and double excitations (CISD). In calculating the potential energy curves, the full valence $\mathrm{CI}$ was employed. The active space of $\mathrm{CI}$ for the $\mathrm{H}_{5} \mathrm{O}_{2}^{+}$and the $\mathrm{H}_{5} \mathrm{O}_{2}^{+}\left(\mathrm{H}_{2} \mathrm{O}\right)_{4}$ molecular systems included six occupied and five lower unoccupied molecular orbitals (more than 40000 configurations with $S=0$ ). Recent benchmark calculations [14] on the database of barrier heights have shown that the results obtained by the CISD method are in a good agreement with experimental data. At the same time, the DFT B3LYP calculations significantly underestimate the barrier energy $[14,15]$.

\subsection{Vibronic coupling treatment of high-symmetry configuration instability}

As always in the JT problems, one starts consideration from a reference configuration at $q=0$, which is defined as that having a relatively high symmetry, for which the first derivatives $(\partial E / \partial Q)_{0}=0$, and assumes that the electronic state $|\Gamma\rangle$ is nondegenerate. According to the PJTE theory [16], the adiabatic potential surface in the space of small displacements $q_{\bar{\Gamma}}(\mathrm{read}$ off from $\varepsilon=0)$ can be described as follows:

$\varepsilon_{0}\left(q_{\bar{\Gamma}}\right)=\frac{1}{2}\left(K_{0 \bar{\Gamma}}^{\Gamma}+K_{v \bar{\Gamma}}^{\Gamma}\right) q_{\bar{\Gamma}}^{2}$

Here, the bare force constant $K_{0 \bar{\Gamma}}^{\Gamma}$,

$K_{0 \bar{\Gamma}}^{\Gamma}=\left\langle\Gamma\left|\left(\partial^{2} \hat{H}\left(r, q_{\bar{\Gamma}}\right) / \partial q_{\bar{\Gamma}}^{2}\right)_{0}\right| \Gamma\right\rangle$,

is related to the contribution of the fixed ground state electron distribution. The second term, $K_{v \bar{\Gamma}}^{\Gamma}$ (which is always negative),

$K_{v \bar{\Gamma}}^{\Gamma}=-2 \sum_{\Gamma^{\prime}}\left|F_{\bar{\Gamma}}^{\Gamma \Gamma^{\prime}}\right|^{2} /\left(E_{\Gamma^{\prime}}-E_{\Gamma}\right)$

is the vibronic contribution to the curvature of the AP arising from the mixing of the ground $(\Gamma)$ with the ex- cited $\left(\Gamma^{\prime}\right)$ electronic states in the second-order perturbation theory, and

$F_{\bar{\Gamma}}^{\Gamma \Gamma^{\prime}}=\left\langle\Gamma\left|\left(\partial \hat{H}\left(r, q_{\bar{\Gamma}}\right) / \partial q_{\bar{\Gamma}}\right)_{0}\right| \Gamma^{\prime}\right\rangle$

is the constant of vibronic coupling between the mixing states. The vibronic constants $F_{\bar{\Gamma}}^{\Gamma \Gamma^{\prime}}$ and, therefore, the vibronic contribution $K_{v \bar{\Gamma}}^{\Gamma}$ to the curvature of the AP are nonzero only if $\Gamma \times \Gamma^{\prime}$ contains $\bar{\Gamma}$.

It was proved analytically and confirmed by a series of numerical calculations [16-20] that, for any molecular system, $K_{0 \bar{\Gamma}}^{\Gamma} \geq 0$. This means that any structural instability and distortions of a high-symmetry configuration of any polyatomic system in a non-degenerate state is caused by and only by the vibronic coupling to appropriate excited states higher in energy. The instability takes place if the inequality $\left|K_{v \bar{\Gamma}}^{\Gamma_{1}}\right| \geq K_{0 \bar{\Gamma}}^{\Gamma}$ holds, i.e. when the vibronic coupling is strong enough, and/or the energy gap between the mixing states is relatively small. It was shown also [17-19] that, in contrast to the widespread thinking, the pseudo Jahn-Teller effect can be essential even for electronic states with large energy level gaps.

Direct calculation of the vibronic coupling matrix elements involved in the PJT models is rather difficult mathematically. In the present work, the values of parameters (primary force constants $K_{0}$ and vibronic coupling constants $V$ ) are estimated by fitting the $a b$ initio data for the APES of molecules to the general formula obtained from the vibronic theory. In the case of the two-level problem, the root of the corresponding secular equation is

$\varepsilon_{0}\left(q_{\bar{\Gamma}}\right)=1 / 2 K_{0 \bar{\Gamma}}^{\Gamma} q_{\bar{\Gamma}}^{2}-\sqrt{\Delta^{2}+V^{2} q_{\bar{\Gamma}}^{2}}$.

\section{Results and Discussion}

\subsection{Quantum chemical calculations of charged hydrogen bonded complexes, $\mathrm{H}^{+}\left(\mathrm{H}_{2} \mathrm{O}\right)_{n}$, $n=6,4,3$}

Protons in liquid water interact with surrounding water molecules forming molecular clusters of the type $\mathrm{H}^{+}\left(\mathrm{H}_{2} \mathrm{O}\right)_{n}$, which can be stable, less stable, or unstable. The most simple and current clusters of the above type correspond to $n=2\left(\mathrm{H}_{5} \mathrm{O}_{2}^{+}\right.$dihydronium cation), $n=4\left(\mathrm{H}_{9} \mathrm{O}_{4}^{+}\right.$cluster $)$and $n=6\left(\mathrm{H}_{13} \mathrm{O}_{6}^{+}\right.$cluster $)$.

In order to determine the possibility of the formation of various charged hydrogen bonded complexes, we make calculations concerning the $\mathrm{H}^{+}\left(\mathrm{H}_{2} \mathrm{O}\right)_{n}$ clusters, in which a proton is surrounded by 6,4 , and 3 water molecules. All the structures are optimized in the most possible 


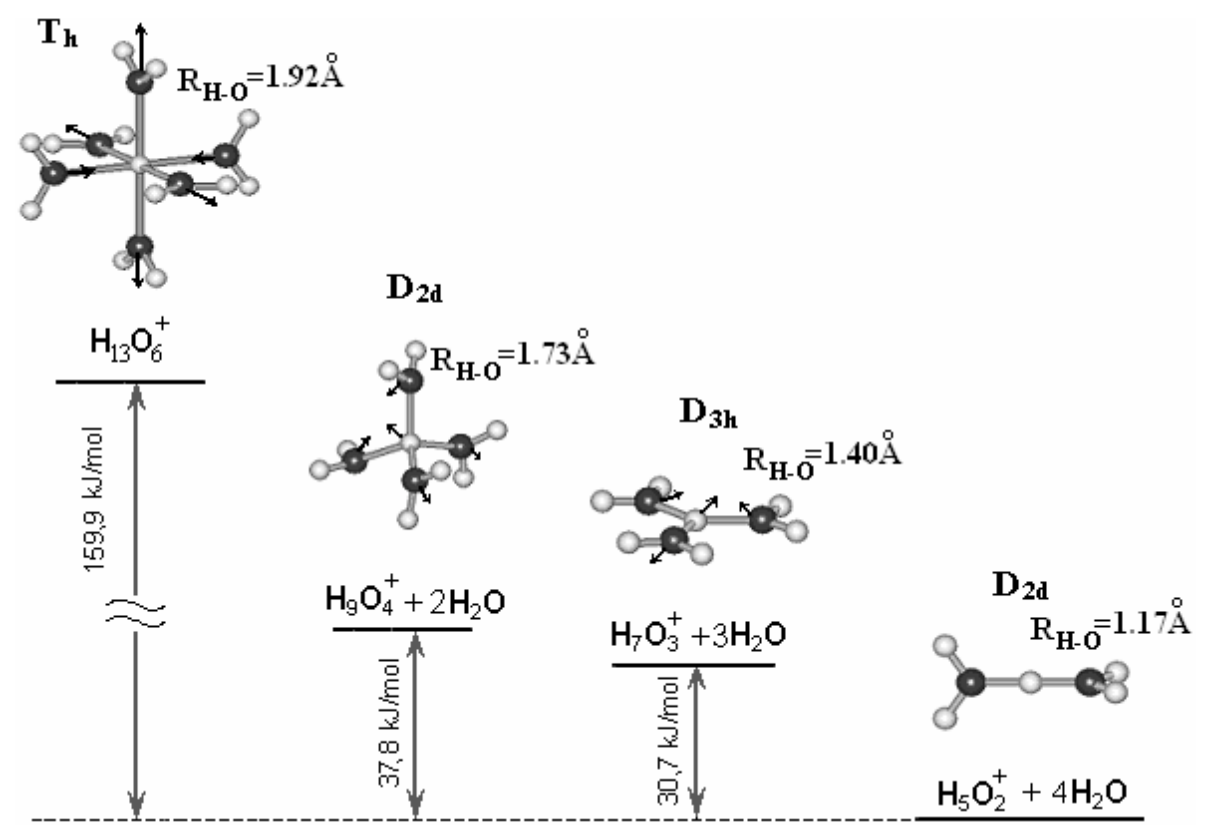

Fig. 1. High-symmetry structures of the $\mathrm{H}^{+}\left(\mathrm{H}_{2} \mathrm{O}\right)_{n}(n=6,4,3)$ clusters, low-symmetry distortions in them leading to their decay ( $e_{g}$-type for $n=6$, e-type for $n=4$, and $e^{\prime}$-type for $n=3$ ), and the PJT stabilization energies of decay

high-symmetry nuclear configurations $\left(T_{h}\right.$ for $n=6, D_{2 d}$ for $n=4$, and $D_{3 h}$ for $\left.n=3\right)$. Then, their stability or instability with respect to low-symmetry distortions $\left(e_{g^{-}}\right.$ type, $e$-type, and $e^{\prime}$-type, respectively, for $n=6,4,3$ ) is studied. From Fig. 1, it is seen that all considered proton-centered water clusters in their highest possible symmetry are unstable with respect to the nuclear displacements, leading to the formation of the dihydronium cation $\mathrm{H}_{5} \mathrm{O}_{2}^{+}: \mathrm{H}_{2 n+1} \mathrm{O}_{n}^{+} \rightarrow(n-2) \mathrm{H}_{2} \mathrm{O}+\mathrm{H}_{5} \mathrm{O}_{2}^{+}$.

In all the cases, the origin of this instability and the following decay are due to the PJT coupling between the ground and excited electronic states of an appropriate symmetry. Thus, such clusters can exist in water only as the short-lived objects that do not affect the properties of water.

\subsection{Pseudo Jahn-Teller effect in the $\mathrm{H}_{5} \mathrm{O}_{2}^{+}$ and $\mathrm{H}_{5} \mathrm{O}_{2}^{+}\left(\mathrm{H}_{2} \mathrm{O}\right)_{4}$ clusters}

The geometry of any molecular system is determined by its electronic structure and the transmutation symmetry of identical atoms. The latter requires to begin the investigation of the possible spatial structures of the systems with its highest possible symmetry. In the case of the $\mathrm{H}_{5} \mathrm{O}_{2}^{+}$and $\mathrm{H}_{5} \mathrm{O}_{2}^{+}\left(\mathrm{H}_{2} \mathrm{O}\right)_{4}$ molecules, the configurations of $D_{2 d}$ and $D_{2 h}$ symmetry are the starting ones. Calculations show that the $D_{2 d}$ structures are lower in energy as compared with the $D_{2 h}$ configurations by the values of $1.7 \mathrm{eV}$ for $\mathrm{H}_{5} \mathrm{O}_{2}^{+}$and $0.2 \mathrm{eV}$ for $\mathrm{H}_{5} \mathrm{O}_{2}^{+}\left(\mathrm{H}_{2} \mathrm{O}\right)_{4}$. The ground-state wavefunctions of both systems belong to the ${ }^{1} A_{1}$ representation of the $D_{2 d}$ symmetry point group, corresponding to a closed-shell electronic configuration. In this geometry, the out-of-center displacement of the central proton toward one of the oxygen atoms is a $b_{2}$-type distortion (Fig. 2). This means that only the excited states of the ${ }^{1} B_{2}$ symmetry contribute to the instability of $D_{2 d}$ configurations with respect to this distortion: $A_{1} \times B_{2}=B_{2}$.

In Fig. 3, the molecular orbitals and the electronic terms of both considered systems are presented. The ${ }^{1} B_{2}$ excited states are formed by the one-electron excitation from the occupied $b_{2}$ molecular orbital to the unoccupied $a_{1}$ MO. It is seen that the energy gap between the ground ${ }^{1} A_{1}$ and the excited ${ }^{1} B_{2}$ states is rather large in both cases. But the vibronic coupling of these states can be strong enough to lead to the instability of the considered nuclear configurations.

Calculations of the total energy of $\mathrm{H}_{5} \mathrm{O}_{2}^{+}$as a function of the proton displacement (at $R_{\mathrm{O}-\mathrm{O}}=2.34 \AA$ optimized in the $D_{2 d}$ structure) showed a single-well adiabatic potential (Fig. 2). This means that the shared proton is located midway between both oxygen atoms, in accordance with the reported experimental data [21] and highlevel ab initio calculations [22]. However, with increasing the $\mathrm{O}-\mathrm{O}$ distance, the APES becomes a double-well one. In Fig. 4, the cross sections of the APES of a di- 

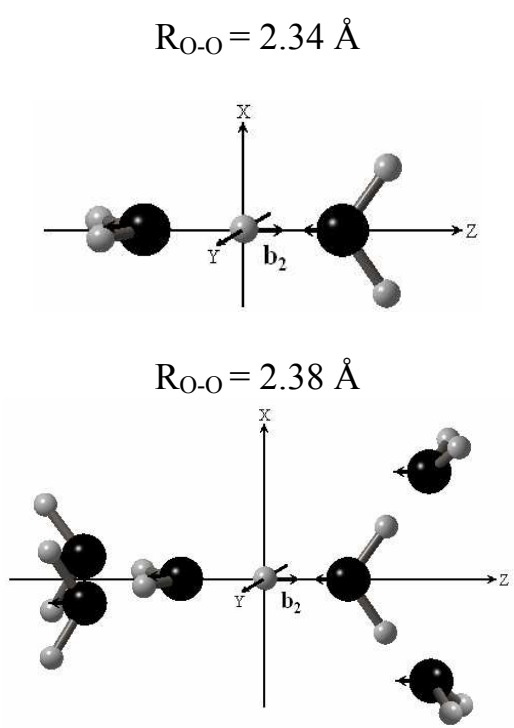
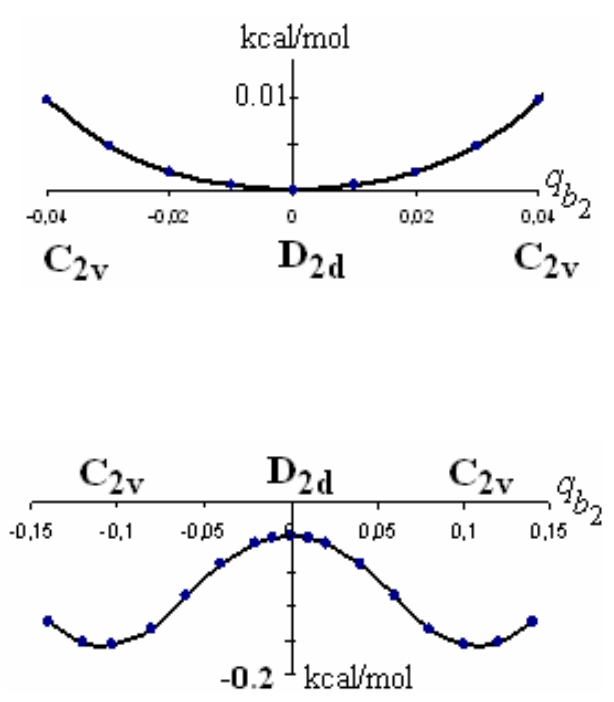

Fig. 2. $D_{2 d}$ structures of $\mathrm{H}_{5} \mathrm{O}_{2}^{+}$and $\mathrm{H}_{5} \mathrm{O}_{2}^{+}\left(\mathrm{H}_{2} \mathrm{O}\right)_{4}$, the $b_{2}$-type distortions (schematically shown by arrows), and the AP curves along the $q_{b 2}$ coordinate

a)

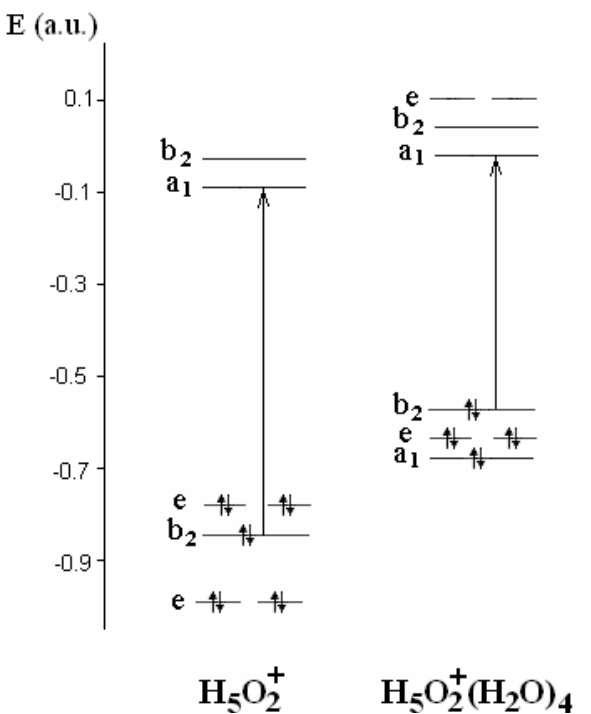

b)

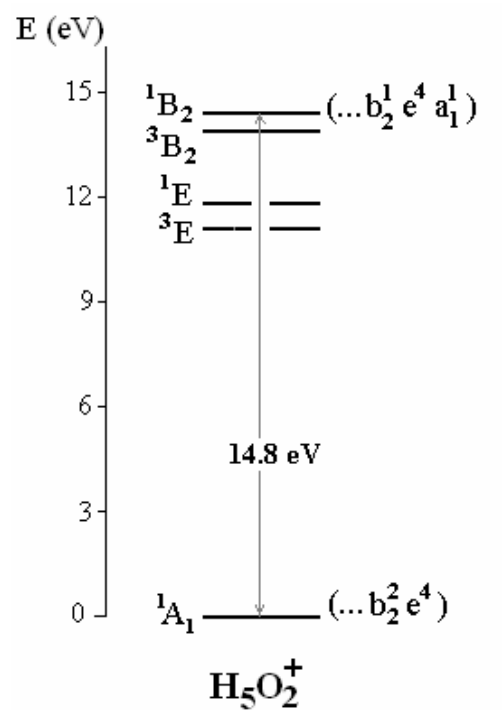

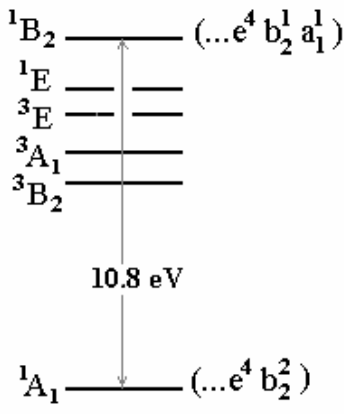

$\mathrm{H}_{5} \mathrm{O}_{2}^{+}\left(\mathrm{H}_{2} \mathrm{O}\right)_{4}$

Fig. 3. MO energy levels $(a)$ and many-electronic states $(b)$ of $\mathrm{H}_{5} \mathrm{O}_{2}^{+}$and $\mathrm{H}_{5} \mathrm{O}_{2}^{+}\left(\mathrm{H}_{2} \mathrm{O}\right)_{4}$ in the $D_{2 d}$ symmetry

hydronium cation along the $b_{2}$ coordinate are shown for several distances $R_{\mathrm{O}-\mathrm{O}}$. As the $q_{b 2}$ coordinate, we use the displacement of a proton from the center of the $\mathrm{O}-\mathrm{O}$ distance.

It is seen that, with increasing the O-O distance, the height and the width of the barrier to proton transfer increases. In Table, the following parameters of the pseudo Jahn-Teller effect are presented: the energy gaps between the ${ }^{1} A_{1}$ and ${ }^{1} B_{2}$ terms, $2 \Delta$, primary force constants $K_{0}$, vibronic coupling constants $V$, and resulting values of the curvature $K=K_{0}-V^{2} / \Delta$. They were obtained, by using the procedure described in Section 2.2. From these data, it follows that the proton transfer from one water molecule to another one can be realized through the energy barrier, whose height and width increase with the $\mathrm{O}-\mathrm{O}$ distance in the $\mathrm{H}_{2} \mathrm{O}-\mathrm{H}-\mathrm{OH}_{2}$ moiety.

Unlike the dihydronium cation $\mathrm{H}_{5} \mathrm{O}_{2}^{+}$, the APES of the $\mathrm{H}_{5} \mathrm{O}_{2}^{+}\left(\mathrm{H}_{2} \mathrm{O}\right)_{4}$ cluster is of a double-well shape (Fig. 2). The high-symmetry $D_{2 d}$ nuclear configuration of $\mathrm{H}_{5} \mathrm{O}_{2}^{+}\left(\mathrm{H}_{2} \mathrm{O}\right)_{4}$ is unstable with respect to an off- 
center displacement of the proton (the $b_{2}$ mode) leading to the stable $C_{2 v}$ nuclear configuration, which is also confirmed by the DFT calculations of this cluster [5]. As in the previous case, the vibronic origin of the proton transfer barrier in this system is revealed by solving the PJT $\left(\left(A_{1}+B_{2}\right) \otimes b_{2}\right.$ problem. The calculated values of PJT parameters in this case are: $K_{0}=55.3$ $\mathrm{eV} / \AA^{2}, V=17.7 \mathrm{eV} / \AA$, the resulting curvature of the AP, $K=-2.7 \mathrm{eV} / \AA^{2}$. From Fig. 3,b, it is seen that, for the $\mathrm{H}_{5} \mathrm{O}_{2}^{+}\left(\mathrm{H}_{2} \mathrm{O}\right)_{4}$ cluster, the energy gap between the mixing ${ }^{1} A_{1}$ and ${ }^{1} B_{2}$ terms is much smaller than that for the Zundel cation $\mathrm{H}_{5} \mathrm{O}_{2}^{+}$. Although the values of $K_{0}$ and $V$ also decrease with the expansion of the cluster, the vibronic contribution $K_{v}$ to the curvature of the AP is substantial enough to satisfy the instability condition $\left|K_{v}\right|>K_{0}$.

The relatively large value of the vibronic constant is due to the nature of the mixing of the ${ }^{1} A_{1}$ and ${ }^{1} B_{2}$ states. In the $D_{2 d}$ nuclear configuration, the excited ${ }^{1} B_{2}$ term arises from the excitation of one electron from the fully occupied molecular orbital $b_{2}$ (formed almost solely from the $2 p_{\sigma}$ AOs of the oxygen atoms) to the unoccupied $a_{1}$ MO that has the significant hydrogen character (Fig. 5). Thus, the wavefunctions of the ground ${ }^{1} A_{1}$ and the excited ${ }^{1} B_{2}$ electronic states differ by one spin-orbital only. Taking into account that the Hamiltonian $H$ in Eq. (4) is a sum of one-particle operators, the vibronic constant $F_{b 2}=\left\langle A_{1}\left|\left(\partial \hat{H}(r, q) / \partial q_{b_{2}}\right)_{0}\right| B_{2}\right\rangle$ is reduced to the matrix element $\left\langle b_{2}\left|\left(\partial H / \partial q_{b 2}\right)_{0}\right| a_{1}\right\rangle$. The large values of vibronic constants are explained by the nature of mixing MOs determining the strong alteration of the binding by a distortion. Indeed, in the high-symmetry $D_{2 d}$ nuclear configuration, the overlap of the occupied $b_{2}$ and unoccupied $a_{1}$ orbitals is zero by symmetry restrictions. Hence, these orbitals do not contribute to the oxygen-hydrogen bonding. Under the $b_{2}$-type nuclear displacements, both $b_{2}$ and $a_{1}$ MOs become of the same symmetry $a_{1}$. Now, their overlap is nonzero resulting in the additional bonding of the $2 p_{\sigma} \mathrm{AO}$ of one of the oxygen atoms with the orbital of the central hydrogen atom.

T a b l e. Parameters of the PJTE for $\mathrm{H}_{5} \mathrm{O}_{2}^{+}$

\begin{tabular}{|c|c|c|c|c|c|}
\hline$R_{\mathrm{O}-\mathrm{O}}(\AA)$ & 2.35 & 2.36 & 2.37 & 2.38 & 2.39 \\
\hline$K_{0}\left(\mathrm{eV} / \AA^{2}\right)$ & 64.76 & 63.95 & 64.67 & 63.63 & 61.99 \\
\hline$V(\mathrm{eV} / \AA)$ & 22.07 & 22.05 & 22.28 & 22.21 & 22.04 \\
\hline$\Delta(\mathrm{eV})$ & 7.413 & 7.412 & 7.412 & 7.411 & 7.410 \\
\hline$K\left(\mathrm{eV} / \AA^{2}\right)$ & -0.92 & -1.61 & -2.28 & -2.93 & -3.54 \\
\hline$h(\mathrm{kcal} / \mathrm{mol})$ & 0.02 & 0.05 & 0.11 & 0.18 & 0.26 \\
\hline$q_{\min }(\AA)$ & 0.06 & 0.08 & 0.09 & 0.10 & 0.11 \\
\hline
\end{tabular}

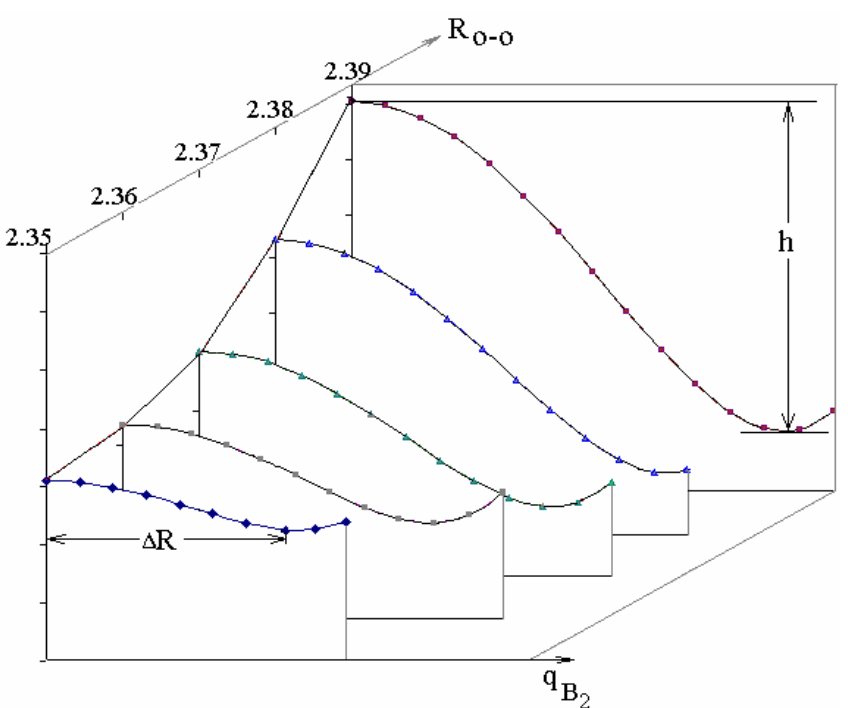

Fig. 4. Cross sections of the APES of $\mathrm{H}_{5} \mathrm{O}_{2}^{+}$along the $b_{2}$ coordinate for several distances $R_{\mathrm{O}-\mathrm{O}}$

\section{Conclusions}

In this work, we have demonstrated that the hydrogen bonds in protonated water clusters can be described in the framework of the pseudo Jahn-Teller effect; all calculated potential energy curves along the off-center proton displacements are fully coincide with those predicted from the general theory.

Calculations confirm also that the breathing mode that controls the O-O distance between two water molecules plays a very important role in the proton transfer dynamics. While in the proton-bounded water dimer $\mathrm{H}_{5} \mathrm{O}_{2}^{+}$, the shared proton is located midway between both oxygen atoms, its ground-state AP as a function of the off-center proton displacement becomes a double-well with increasing the O-O distance. Accounting for only the first solvation sphere around the Zundel cation in the $\mathrm{H}_{5} \mathrm{O}_{2}^{+}\left(\mathrm{H}_{2} \mathrm{O}\right)_{4}$ cluster leads to a double-well adiabatic potential energy surface along the hydrogenbond coordinate and to the instability of the on-center position of the shared proton.

This instability is shown to originate from the pseudo Jahn-Teller mixing of the electronic ${ }^{1} A_{1}$ ground state with the excited state of ${ }^{1} B_{2}$ symmetry through the asymmetric $b_{2}$ vibrational mode. Though the energy gap between the mixing states is rather large, the pseudo Jahn-Teller effect on the off-center displacement of the central proton toward one of the oxygen atoms is rather strong due to the relatively large vibronic constant. The latter, in its turn, is due to the nature of the mixing MOs 

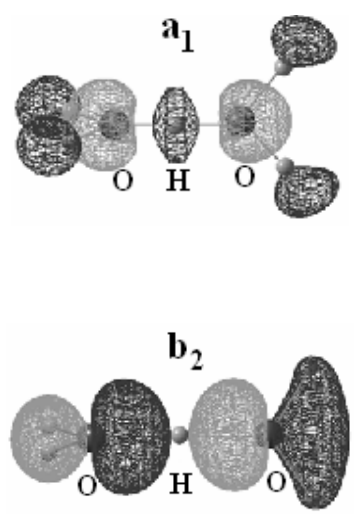

(a)

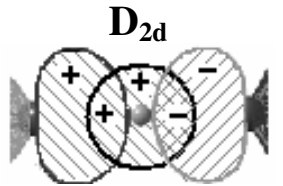

$\mathrm{C}_{2 \mathrm{v}}$

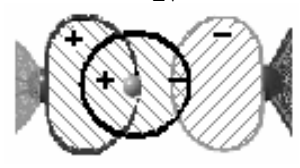

(b)

Fig. 5. (a) Vibronically mixing molecular orbitals: occupied MO $b_{2}$ and unoccupied MO $a_{1}$; $(b)$ schematic illustration to the covalency origin of the vibronic instability of the $D_{2 d}$ configuration of the $\mathrm{H}_{5} \mathrm{O}_{2}$ moiety: $b_{2} \otimes a_{1}$. The overlap integral between the vibronically mixing molecular orbitals is zero in the $D_{2 d}$ configuration and becomes nonzero by the $b_{2}$ distortion, shifting the proton toward one of the oxygen atoms

determining the strong alteration of the binding by the distortion.

The high-symmetry proton-centered water clusters $\mathrm{H}^{+}\left(\mathrm{H}_{2} \mathrm{O}\right)_{n}$ with $n>2$, even without considering lowsymmetry surroundings, are unstable with respect to low-symmetry nuclear displacements, leading to the formation of the dihydronium cation $\mathrm{H}_{5} \mathrm{O}_{2}^{+}$and water molecules: $\mathrm{H}_{2 n+1} \mathrm{O}_{n}^{+} \rightarrow(n-2) \mathrm{H}_{2} \mathrm{O}+\mathrm{H}_{5} \mathrm{O}_{2}^{+}$. The origin of this instability is due to the PJT coupling between the ground and excited electronic states of the appropriate symmetry. Thus, such clusters can exist in water only as short-lived objects that do not affect the properties of water.

1. G.E. Douberly, R.S. Walters, J. Cui, K.D. Jordan, and M.A. Duncan, J. Phys. Chem. A 114, 4570 (2010).

2. J-C. Jiang, Yi-S. Wang, Hai-Chou Chang, S.H. Lin, Y.T. Lee, G. Niedner-Schatteburg, and Huan-Cheng Chang, J. Am. Chem. Soc. 122, 1398 (2000).

3. H.M. Lee, P. Tarakeshwar, J. Park, M.R. Koiaski, Y.J. Yoon, Hai-Bo Yi, W.Y. Kim, and K.S. Kim, J. Phys. Chem. A 108, 2949 (2004).

4. Yi Luo, S. Maeda, and K. Ohno, J. Phys. Chem. A 111, 10732 (2007).

5. M. Park, I. Shin, N.J. Singh, and K.S. Kim, J. Phys. Chem. A 111, 10692 (2007).

6. I.B. Bersuker, N.N. Gorinchoy, and T.A. Fedorco, Ferroelectrics, 153, 1 (1994).
7. H. Köppel, W. Domcke, and L.S. Cederbaum, Adv. Chem. Phys. 57, 59 (1984).

8. P. García-Fernández, J.A. Aramburu, M.T. Barriuso, and M. Moreno, Phys. Rev. B 69, 174110 (2004); 73, 184122 (2006).

9. M. Moreno, M.T. Barriuso, J.A. Aramburu, P. GarcíaFernández, and J.M. García-Lastra, J. Phys.: Condens. Matter 18, R315 (2006).

10. P. García-Fernández, L. García-Canales, J.M. GarcíaLastra, J. Junquera, M. Moreno, and J.A. Aramburu1, J. Chem. Phys. 129, 124313 (2008).

11. A.A. Granovsky, www.http://classic.chem.msu.su/gran/ gamess/index.html.

12. M.W. Schmidt, K.K. Baldridge, J.A. Boatz, S.T. Elbert, M.S. Gordon, J.H. Jensen, S. Koseki, N. Matsunaga, K.A. Nguyen, S. Su, T.L. Windus, M. Dupuis, and J.A. Montgomery, J. Comput. Chem. 14, 1347 (1993).

13. T.H. Dunning, J. Chem. Phys. 55, 716 (1971).

14. Y. Zhao and D.G. Truhlar, J. Phys. Chem. A 109, 6624 (2005).

15. B.J. Lynch and D.G. Truhlar, J. Phys. Chem. A 105 , 2936 (2001); B.J. Lynch and D.G. Truhlar, J. Phys. Chem. A 107, 8996 (2003); Y. Zhao, B.J. Lynch, and D.G. Truhlar, J. Phys. Chem. A 108, 2715 (2004); Y. Zhao, N. González-García, and D.G. Truhlar, J. Phys. Chem. A 109, 2012 (2005); P. García Fernández, C. Sousa, J.A. Aramburu, M.T. Barriuso, and M. Moreno, Phys. Rev. B 72, 155107 (2005). 
16. I.B. Bersuker, The Jahn-Teller Effect (Cambridge Univ. Press, Cambridge, 2006), Ch. 4.1, p. 110.

17. I.B. Bersuker, N.N. Gorinchoi, and V.Z. Polinger, Theor. Chim. Acta 66, 161 (1984).

18. V.Z. Polinger, N.N. Gorinchoi, and I.B. Bersuker, Chem. Phys. 159, 75 (1992).

19. N.N. Gorinchoi, F. Cimpoesu, and I.B. Bersuker, J. Mol. Struct. (Theochem), 530, 281 (2001).

20. I. Ogurtsov, N. Gorinchoy, and I. Balan, J. Mol. Struct. 838, 107 (2007).

21. T. James and D.J. Wales, J. Chem. Phys. 122, 134306 (2005).

22. E.G. Dicken, J.M. Headrick, J.R. Roscoli, J.C. Bopp, M.A. Johnson, and A.B. McCoy, J. Phys. Chem. A 109, 1487 (2005).

Received 21.01.11

\section{ПСЕВДОЕФЕКТ ЯНА-ТЕЛЛЕРА ЯК ПРИЧИНА ТУНЕЛЮВАННЯ ПРОТОНА В КЛАСТЕРАХ ВОДИ, ЩО МІСТЯТЬ КАТІОН ЦУНДЕЛЯ}

I. Жеру, Н. Горінчой, I. Балан

$\mathrm{P}$ е $з$ ю м е

Розрахунками ab initio електронної структури та кривих адіабатичного потенціалу катіона Цунделя для різних відстаней O-O і кластера $\mathrm{H}_{5} \mathrm{O}_{2}^{+}\left(\mathrm{H}_{2} \mathrm{O}\right)_{4}$ показано, що бар'єр для переносу протона зобов'язаний своїм походженням псевдо-ефекту ЯнаТеллера. Зіставлення розрахункових і аналітичних кривих адіабатичного потенціалу дозволило оцінити вібронні константи. Показано, що високосиметричні ядерні конфігурації кластерів води 3 протоном у центрі типу $\mathrm{H}^{+}\left(\mathrm{H}_{2} \mathrm{O}\right)_{n}(n=6,4,3)$ нестабільні щодо низькосиметричних збурень, що приводять до утворення катіона дигідронію $\mathrm{H}_{5} \mathrm{O}_{2}^{+}$і відповідного числа молекул води: $\mathrm{H}_{2 n+1} \mathrm{O}_{n}^{+} \rightarrow(n-2) \mathrm{H}_{2} \mathrm{O}+\mathrm{H}_{5} \mathrm{O}_{2}^{+}$. Причиною цієї нестабільності і подальшого розпаду є псевдо-ян-теллерівський зв'язок основного і збудженого електронних станів. 